\title{
Summary Measures of Population Health: Addressing the First Goal of Healthy People 2010, Improving Health Expectancy
}

\author{
Diane K. Wagener, Ph.D.; Michael T. Molla, Ph.D.; Eileen M. Crimmins, Ph.D.; Elsie Pamuk, Ph.D.; \\ and Jennifer H. Madans, Ph.D.
}

\section{Abstract}

This report is one of several Healthy People Statistical Notes that evaluate methodological issues pertaining to summary measures - statistics that combine mortality and morbidity data to represent overall population health in a single number. This report evaluates the consequences of changes in the components of health expectancy measures (i.e., mortality or morbidity) on the overall measure. Any activity limitation is used as a morbidity measure. Simulations are used to evaluate the impacts of reducing 1995 age-specific mortality or activity limitation rates by $5,10,25$, and 50 percent at all ages. Then it is limited to ages under 25 years, 25-64 years, and over 64 years. The impact of completely eliminating mortality or activity limitation for the younger age groups is also examined. In general, reducing morbidity rates results in greater changes than the same percent reduction in death rates. The same proportional reduction in age-specific rates for either mortality or morbidity has a greater impact if it occurs at older ages. Reducing mortality results in a greater change in life expectancy than in health expectancy and a decline in the proportion of life lived in healthy states. Reducing morbidity increases both health expectancy and the proportion of life lived in healthy states. Simultaneous reductions in mortality and morbidity have additive effects on health expectancy.

Keywords: summary measures $\bullet$ health expectancy $\bullet$ disability-free life expectancy $\bullet$ life expectancy

\section{Introduction}

The increase in life expectancy during the 20th century has been a remarkable achievement, rising from 47 years in 1900 to almost 76 years in 1995 (1), an increase of more than 60 percent. One of the overarching goals of Healthy People 2010 (2) is to increase the quality and years of healthy life. This goal targets not only a continued increase in life expectancy (dependent on reduced mortality), but also an improvement in the percent of life lived with good health (dependent on reduced morbidity). Therefore, summary measures of population health are being evaluated as statistics that could be used to monitor success in addressing this goal. Summary measures of population health are defined by the Institute of Medicine as measures "that combine both mortality and morbidity data to represent overall population health in a single number (e.g., health-adjusted life years or health-adjusted life expectancy)" (3). More specifically, summary measures of population health (hereafter referred to as "summary measures") combine age-specific morbidity (health) and mortality rates to derive a single measure of population health. These measures have been proposed as the most comprehensive measures for evaluating overall trends and differences in population health (4).

Public health programs and policies are designed to reduce mortality and morbidity in the population. This report evaluates the effects of change in these two components of summary measures. No specific public health program or policy is evaluated; hypothesized, simple percent changes in age-specific mortality or morbidity rates at all ages and for 
specific age groups are examined. These analyses provide a sense of the magnitude of changes in summary measures of population health that might be expected for public health programs. Barendregt (5) evaluated disease-specific changes and the consequences for disability-adjusted life expectancy for five diseases having major consequences for mortality and morbidity. The consequences of reducing mortality and morbidity broadly are examined.

Many potential summary measures have been proposed (4). As part of Healthy People 2000, the Years of Healthy Life measure was developed to monitor a similar goal $(6,7)$. This measure combines the age-specific mortality rates with a morbidity variable that is a weighted average of respondent-assessed health status and limitation of activity caused by chronic health conditions. Because the morbidity-related variable is multivariate, interpretation of sensitivity analyses is complicated. However, the analyses presented in this report focus on a simple health-adjusted life expectancy measure (hereafter referred to as health expectancy) that combines total mortality and a univariate measure of morbidity using the methods described by Sullivan (8). Details on the calculation of health expectancy measures have been published (9). Health expectancy statistics are presented for reports of any activity limitation due to impairments or health problems, largely chronic health conditions. Because activity limitation is used as an indicator of disability, these health expectancy statistics may also be referred to as disability-free life expectancy.

Health expectancy is often interpreted as the number of years an average person is expected to live in good health. Because populations usually have less than good health, the number of expected healthy years is less than expected life years. Consequently, the difference is sometimes referred to as unhealthy years. All the unhealthy years are not necessarily lived at the end of life and could be distributed throughout a lifetime. Health expectancy, when viewed in the context of total life expectancy (i.e., as a proportion of total life expectancy), can also be interpreted as the proportion of life lived in a healthy state. On an individual level, an increase in the proportion of healthy life is an increase in the percent of an average year that is lived in a healthy state. On a population level, health expectancy as a proportion of life expectancy can be interpreted as the average proportion of the population that is healthy in a given year. An increase, therefore, would be an increase in the proportion of the population experiencing healthy life.

It is important to note that as with life expectancy, health expectancy does not refer to the health experience over a lifetime of an actual population. Health expectancy is the number of years a hypothetical population would live in a given healthy state if it experienced throughout life the mortality and morbidity rates of the specific year being considered, in this 1995 report.

In this report, different sets of assumptions about change in the components are systematically applied to alter real data to assess the resulting changes in health expectancy. Many models might be proposed for reducing mortality and/or morbidity rates. Simple models of equal proportional reductions in either mortality or morbidity for specific ages are used. Crimmins et al. (10) presented similar analyses to evaluate consequences on summary measures of health for adults aged 70 years and older. In this segment of the population, reducing mortality without reducing morbidity increases both the years and the proportion that is unhealthy life. Conversely, reducing morbidity without reducing mortality reduced both the years and the proportion of life that is unhealthy. In the following analyses, changes in age-specific mortality or age-specific activity limitation due to chronic health conditions are applied separately to four categories: all ages, children and young adults (less than age 25 years), adults (ages 25-64 years), and older adults (65 years and older). These analyses are evaluated for their impact on summary measures of population health. Hypothetical reductions are applied to mortality rates for 1995 , to activity limitation rates for 1995 , and jointly to the mortality and activity limitation rates. In each section, the impact on life expectancy and on years free of activity limitation (the health expectancy measure evaluated in this report), the relative impact of changing the size of the reduction, and the relative impact of reductions in the different age groups are discussed. These impacts are then compared to the observed changes in life expectancy and years free of activity limitation for the decade between 1985 and 1995.

\section{Changes in Life and Health Expectancy, 1985 to 1995}

To gauge the size of changes in age-specific mortality or morbidity rates that are possible, changes that have occurred in the U.S. population were explored. As noted above, life expectancy has changed dramatically in the past century. Between 1900 and 1995, life expectancy at birth increased 57 and 63 percent, respectively, for males and females (from 46.3 to 72.5 years for males and from 48.3 to 78.9 for females (1)). Figures 1 and 2 compare age-specific total mortality rates used to calculate the expected years of life for 1900 and 1995, presented separately for males and females (see table I). Remarkable decreases over time are noted among children, particularly those under 5 years of age (about a 97-percent decrease for both sexes). Although changes are apparent for those aged 25-64 years, the magnitude of the death rates is relatively small. Among those aged 65 years or older, age-specific mortality decreased 35 to 45 percent among men and 40 to 55 percent among women between 1990 and 1995 .

Although substantial changes occurred early in the century, changes in mortality, and consequently life expectancy, continued in the recent past. Table 1 presents age-adjusted mortality for 1985 and 1995. During this decade, mortality decreased 8.2 percent, from 548.9 per 100,000 population in 1985 to 503.9 in 1995 (1). For subpopulations, the change over the decade varied. Reductions in mortality were greatest among white males 


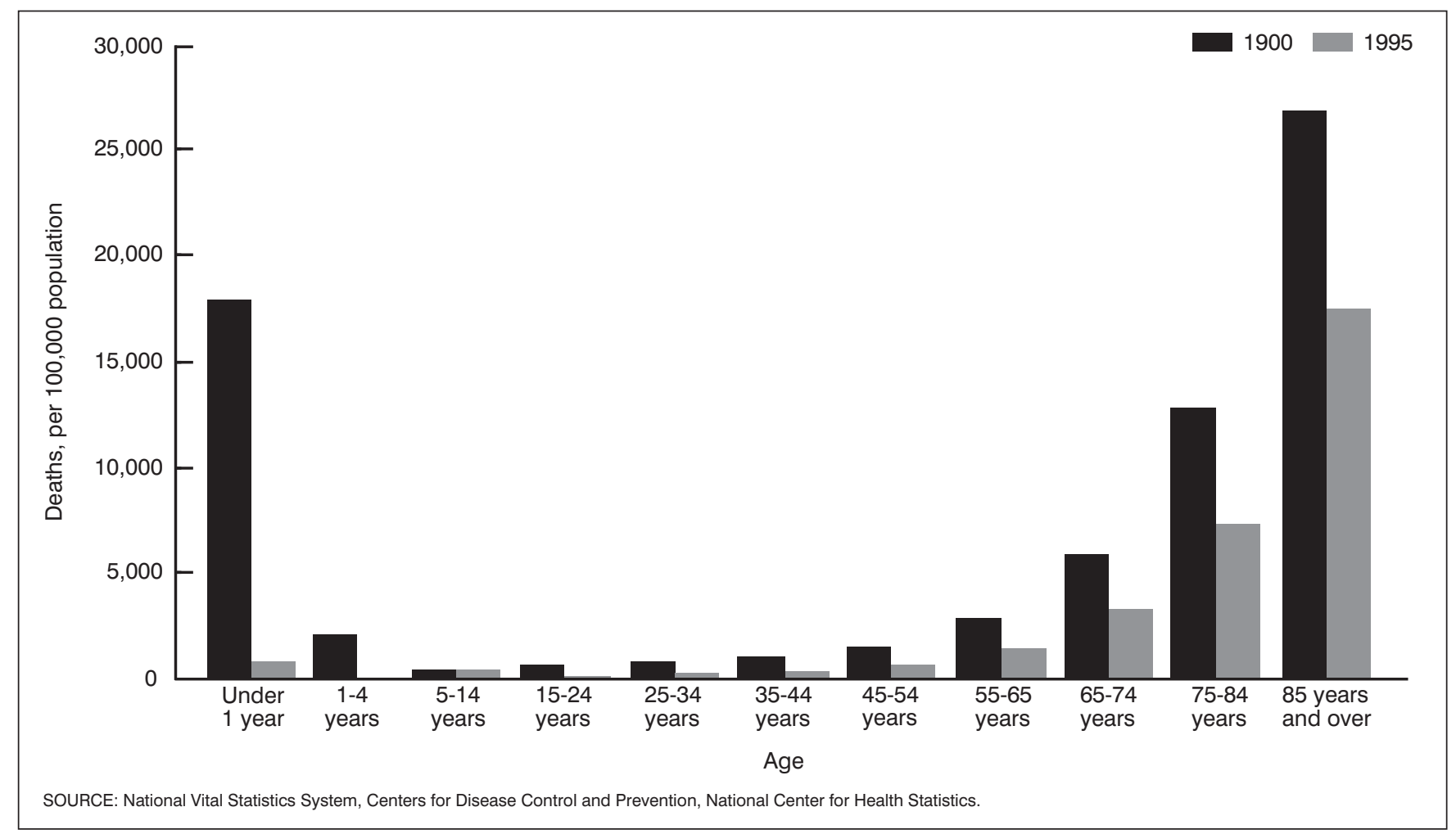

Figure 1. Death rates among males by age: United States, 1900 and 1995

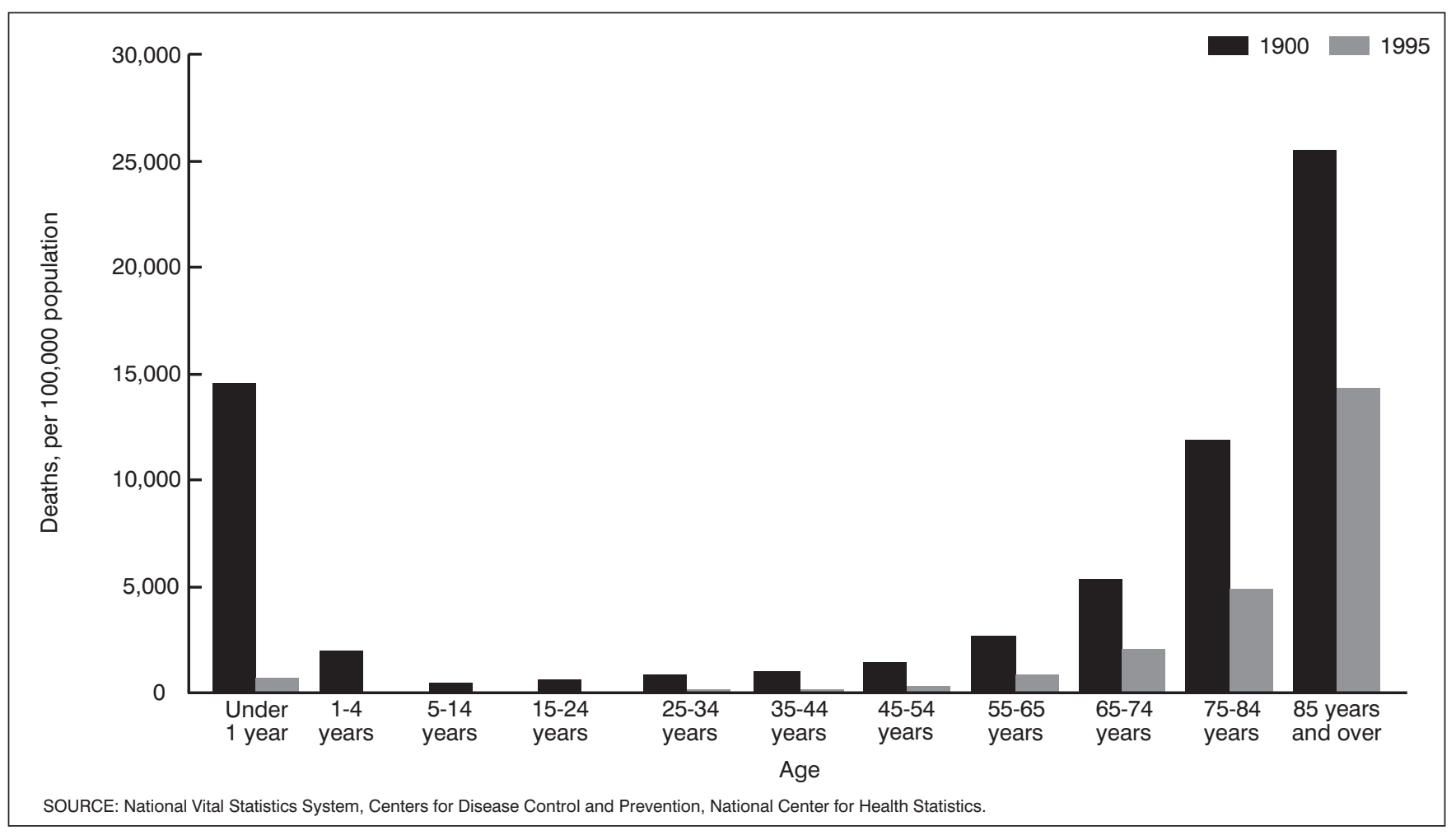

Figure 2. Death rates among females by age: United States, 1900 and 1995 
Table 1. Mortality rate and percent of people with any limitation of activity due to chronic health conditions, by race and sex: United States, 1985 and 1995

\begin{tabular}{|c|c|c|c|c|c|c|c|c|c|}
\hline & \multirow[b]{2}{*}{ Population } & \multicolumn{4}{|c|}{ Total mortality ${ }^{1}$} & \multicolumn{4}{|c|}{ Any activity limitation ${ }^{1}$} \\
\hline & & 1985 & 1995 & $\Delta^{2}$ & Percent $\triangle^{3}$ & 1985 & 1995 & $\Delta^{2}$ & Percent $\triangle^{3}$ \\
\hline & & \multicolumn{4}{|c|}{ Deaths per 100,000 population } & \multicolumn{4}{|c|}{ Percent } \\
\hline \multirow[t]{2}{*}{ Total. } & & 548.9 & 503.9 & -45.0 & -8.2 & 12.4 & 13.1 & 0.7 & 5.3 \\
\hline & White & & & & & & & & \\
\hline Males. . & $\cdots$ & 693.3 & 610.5 & -82.8 & -11.9 & 12.4 & 13.1 & 0.7 & 5.7 \\
\hline \multirow[t]{2}{*}{ Females } & & 391.0 & 364.9 & -26.1 & -6.7 & 11.6 & 12.5 & 0.9 & 7.4 \\
\hline & Black & & & & & & & & \\
\hline Males. & & $1,053.4$ & $1,016.7$ & -36.7 & -3.5 & 15.1 & 17.0 & 1.9 & 13.2 \\
\hline Females & & 594.8 & 571.0 & -23.8 & -4.0 & 15.2 & 16.1 & 0.9 & 5.5 \\
\hline
\end{tabular}

${ }^{1}$ Mortality and frequency of activity limitation due to chronic health conditions are age-adjusted to 1940 standard population.

${ }^{2} \triangle$ is the difference between 1985 and 1995: 1995 value - 1985 value.

${ }^{3}$ Percent $\triangle$ is the percent difference between 1985 and 1995: $\triangle / 1985$ value.

SOURCES: Centers for Disease Control and Prevention, National Center for Health Statistics. National Vital Statistics System (mortality); National Health Interview Survey (noninstitutionalized population); National Nursing Home Survey (nursing home population).

and least among black males. Because mortality decreased between 1985 and 1995, life expectancy at birth for the total population increased 1.1 years to 75.8 years, an increase of 1.5 percent (table 2). White males had the largest increase, and black males had the least increase. For white and black females, the increase in expected life was about 1 percent.

Health change may be viewed as a process with multiple dimensions: diseases, conditions, and impairments; loss of function; disability; and death (11). Over time, change can occur in some or all of these dimensions. The incorporation of mortality in the calculation of health expectancy assures that changes in the death dimension are reflected in the measure. However, there are many choices of morbidity measures that could be used in summary measures. In this report, any activity limitation due to chronic health conditions are used. This is a measure of disability. Figure 3 presents age-specific rates for mortality and activity limitation in 1995 (table II).

The proportion of the population with activity limitation due to chronic health conditions (hereafter referred to as activity limitation) increased between 1985 and 1995 (table 1). For the total population, the age-adjusted proportion increased 5.3 percent. Large differences in activity limitation occur for subgroups of the population. In 1995 , the percent of black males reporting any activity limitation due to chronic health conditions was $11 / 3$ times the rate for white females. Further, the increases were the largest for black males, both in terms of actual increase and percent increase. They were the smallest for white males. The increase among black males was almost 3 times that of white males.

Using age-specific mortality and activity limitation, the health expectancy statistic (expected years free of activity limitation) can be calculated utilizing life table procedures (see appendix and Healthy People Statistical Notes no. 21 (9)). In 1995, expected years free of activity limitation for the total population was 62.2 years (table 2). This was a slight increase in expected years free of activity limitation (1.0 percent), although the total frequency of activity limitation increased (table 1). This

Table 2. Life expectancy and number of expected years free of any activity limitation due to chronic health conditions, by race and sex: United States, 1985 and 1995

\begin{tabular}{|c|c|c|c|c|c|c|c|c|c|}
\hline & \multirow[b]{2}{*}{ Population } & \multicolumn{4}{|c|}{$\begin{array}{c}\text { Expected } \\
\text { years of life }\end{array}$} & \multicolumn{4}{|c|}{$\begin{array}{l}\text { Expected years free of } \\
\text { activity limitation }\end{array}$} \\
\hline & & 1985 & 1995 & $\triangle^{1}$ & Percent $\triangle^{2}$ & 1985 & 1995 & $\triangle^{1}$ & Percent $\triangle^{2}$ \\
\hline \multirow[t]{2}{*}{ Total. . } & $\ldots \ldots \ldots \ldots \ldots \ldots \ldots$ & 74.7 & 75.8 & 1.1 & 1.5 & 61.6 & 62.2 & 0.6 & 1.0 \\
\hline & White & & & & & & & & \\
\hline Males. . & $\ldots$ & 72.0 & 73.7 & 1.7 & 2.4 & 60.5 & 61.1 & 0.6 & 1.0 \\
\hline \multirow[t]{2}{*}{ Females } & $\ldots \ldots \ldots \ldots$ & 78.6 & 79.5 & 0.9 & 1.1 & 64.9 & 64.8 & -0.1 & -0.2 \\
\hline & Black & & & & & & & & \\
\hline Males. . & $\ldots \ldots \ldots \ldots \ldots$ & 65.0 & 65.4 & 0.4 & 0.6 & 53.3 & 52.6 & -0.7 & -1.3 \\
\hline Females & 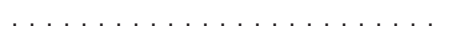 & 73.2 & 73.9 & 0.7 & 1.0 & 57.2 & 57.4 & 0.2 & 0.3 \\
\hline
\end{tabular}

${ }^{1} \triangle$ is the difference (in years): 1995 value -1985 value.

${ }^{2}$ Percent $\triangle$ is the percent difference between 1985 and 1995: $\triangle / 1985$ value.

SOURCES: Centers for Disease Control and Prevention, National Center for Health Statistics. National Vital Statistics System (mortality); National Health Interview Survey (noninstitutionalized population); National Nursing Home Survey (nursing home population). 


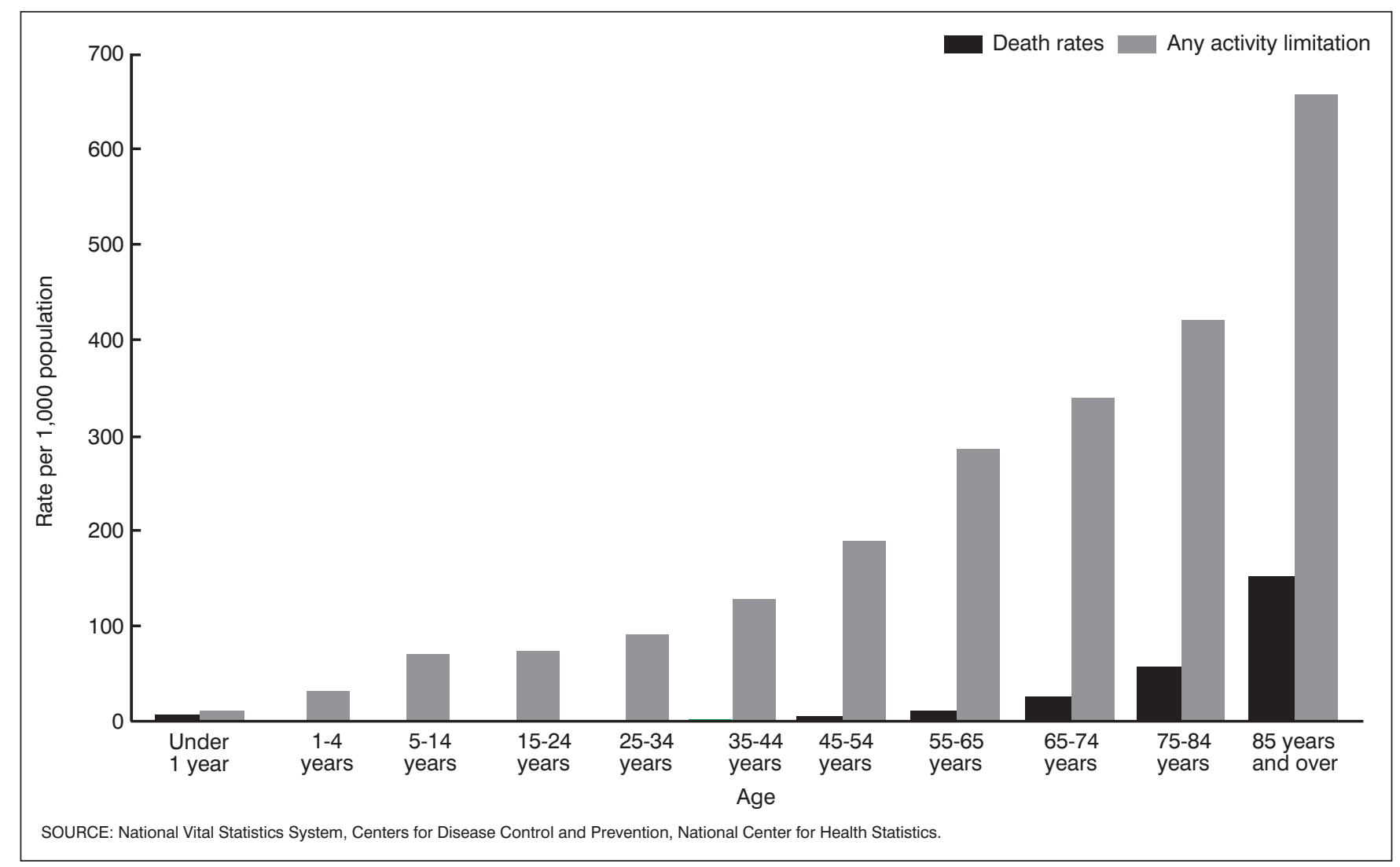

Figure 3. Death and reported activity limitation rates by age: United States, 1995

apparent contradiction can be attributed to a decrease in the other principal component of health expectancy, mortality. The change in expected years free of activity limitation differed between subgroups of the population. Expected years free of activity limitation increased among white males and black females, but decreased among the other race-gender groups. Among black males, expected years free of activity limitation decreased by 0.7 years.

\section{Effects of Changing Mortality}

The following analyses determine how sensitive this summary measure is to reductions in mortality. To evaluate the effect of changing mortality on both life expectancy and expected years free of activity limitation, the effects of simulated changes were examined. Age-specific rates for designated age ranges were reduced proportionally, and the life and health expectancies were recalculated in a series of models. Reductions of 5, 10, 25, and 50 percent were applied to the observed 1995 5-year mortality rates (table II) for four sets of age groups-all ages, less than 25 years, 25-64 years, and 65 years and older. In another model, complete elimination of mortality (i.e., a 100-percent reduction) was assessed for children and young adults and for adults 25-64 years old. For these analyses, morbidity rates - the other principle component of health expectancy-was not altered. The results of these analyses, using activity limitation as the measure of morbidity, are shown in table 3 .
In $1995,35.6$ percent of the population was less than 25 years of age, 51.6 percent were ages 25-64 years, and the remaining 12.8 percent were aged 65 years or older (12). These age groups were chosen because the functions required for daily activities differ substantially among these age groups (e.g., school, work, or recreational activities). Another reason for choosing these age groups is that the most common adverse health conditions differ-as evidenced by the leading causes of death (1) (e.g., congenital anomalies and unintentional injuries among the young and malignant neoplasms and diseases of the heart among the middle and older age groups) and most frequent first-listed diagnosis on hospital discharge records (1) (e.g., pneumonia and injuries or poisonings among the young, injuries and diseases of the heart among the middle ages, and diseases of the heart, cerebrovascular diseases, and pneumonia among the older population). Consequently, the health experience for these three age groups differs and the evaluation of "quality health" also differs.

\section{Life Expectancy Versus Health Expectancy}

Reductions in mortality have a larger effect (i.e., a greater increase) on life expectancy than on expected years free of activity limitation (table 3 ). For example, focusing on the models in which mortality is reduced at all ages, a 5 -percent reduction increases life expectancy by 0.6 years, but expected years free of activity limitation by only 0.3 years. When mortality is reduced 50 percent, the resulting 
Table 3. Life expectancy and number of expected years free of any activity limitation due to chronic health conditions by several models of reduced mortality without reduced activity limitation

\begin{tabular}{|c|c|c|c|c|c|c|c|}
\hline \multirow[b]{2}{*}{ Model $^{1}$} & \multicolumn{3}{|c|}{$\begin{array}{c}\text { Expected } \\
\text { years of life }\end{array}$} & \multicolumn{4}{|c|}{$\begin{array}{c}\text { Expected years free of } \\
\text { activity limitation }\end{array}$} \\
\hline & Years & $\Delta^{2}$ & Percent $\triangle^{3}$ & Years & $\begin{array}{l}\text { Percent } \\
\text { of } L^{4}\end{array}$ & $\Delta^{2}$ & Percent $\triangle^{3}$ \\
\hline & \multicolumn{7}{|c|}{ No reduction in age-specific mortality } \\
\hline \multirow[t]{2}{*}{$\ldots$} & 75.8 & $\cdots$ & $\cdots$ & 62.2 & 82.1 & $\cdots$ & $\cdots$ \\
\hline & \multicolumn{7}{|c|}{ 5-percent reduction in age-specific mortality } \\
\hline 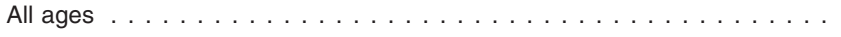 & 76.4 & 0.6 & 0.8 & 62.5 & 81.8 & 0.3 & 0.5 \\
\hline 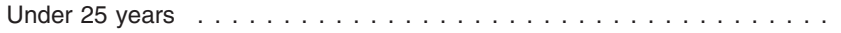 & 75.9 & 0.1 & 0.1 & 62.2 & 81.9 & 0.0 & 0.0 \\
\hline 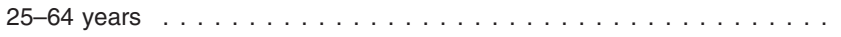 & 76.1 & 0.3 & 0.4 & 62.3 & 81.8 & 0.1 & 0.2 \\
\hline \multirow[t]{2}{*}{ 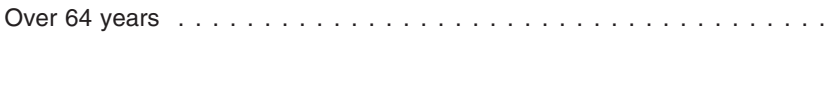 } & 76.1 & 0.3 & 0.4 & 62.3 & 81.8 & 0.1 & 0.2 \\
\hline & \multicolumn{7}{|c|}{ 10-percent reduction in age-specific mortality } \\
\hline 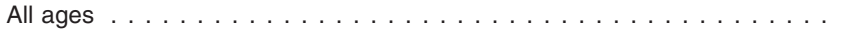 & 77.0 & 1.2 & 1.6 & 62.8 & 81.6 & 0.6 & 1.0 \\
\hline 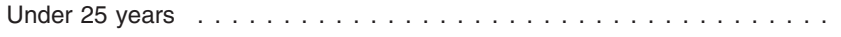 & 76.0 & 0.2 & 0.3 & 62.3 & 82.0 & 0.1 & 0.2 \\
\hline 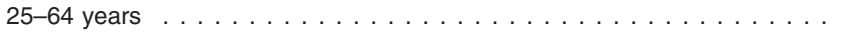 & 76.3 & 0.5 & 0.7 & 62.5 & 81.9 & 0.3 & 0.5 \\
\hline \multirow[t]{2}{*}{ 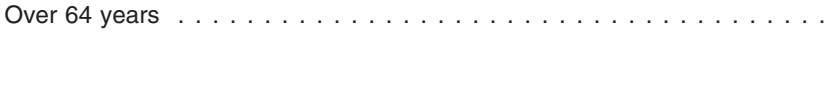 } & 76.3 & 0.5 & 0.7 & 62.4 & 81.8 & 0.2 & 0.3 \\
\hline & \multicolumn{7}{|c|}{ 25-percent reduction in age-specific mortality } \\
\hline 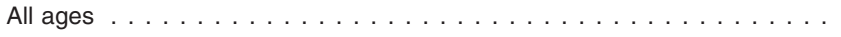 & 78.8 & 3.0 & 4.0 & 63.9 & 81.1 & 1.7 & 2.7 \\
\hline 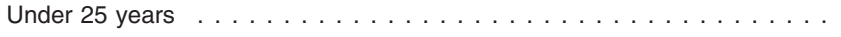 & 76.2 & 0.4 & 0.5 & 62.4 & 81.9 & 0.2 & 0.3 \\
\hline 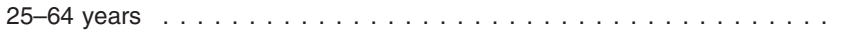 & 77.1 & 1.3 & 1.7 & 63.0 & 81.7 & 0.8 & 1.3 \\
\hline \multirow[t]{2}{*}{ 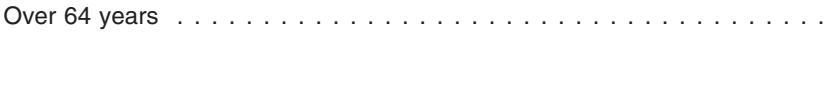 } & 77.2 & 1.4 & 1.8 & 62.8 & 81.3 & 0.6 & 1.0 \\
\hline & \multicolumn{7}{|c|}{ 50-percent reduction in age-specific mortality } \\
\hline 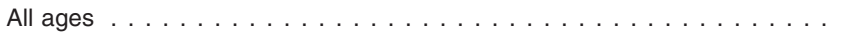 & 82.2 & 6.4 & 8.4 & 65.9 & 80.2 & 3.7 & 5.9 \\
\hline 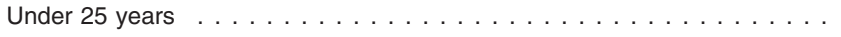 & 76.5 & 0.7 & 0.9 & 62.7 & 82.0 & 0.5 & 0.8 \\
\hline 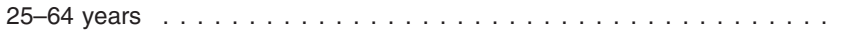 & 78.3 & 2.5 & 3.3 & 63.8 & 81.5 & 1.6 & 2.6 \\
\hline \multirow[t]{2}{*}{ 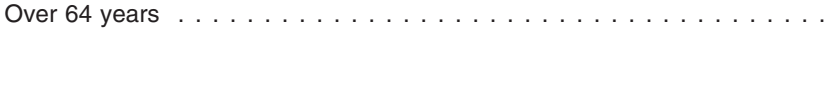 } & 78.7 & 2.9 & 3.8 & 63.6 & 80.8 & 1.4 & 2.3 \\
\hline & \multicolumn{7}{|c|}{ Complete elimination of age-specific mortality } \\
\hline 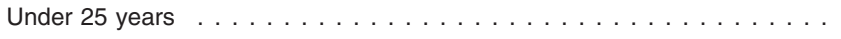 & 77.2 & 1.4 & 1.8 & 63.3 & 82.0 & 1.1 & 1.8 \\
\hline 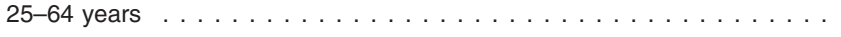 & 81.0 & 5.2 & 6.9 & 65.5 & 80.9 & 3.3 & 5.3 \\
\hline
\end{tabular}

. Category not applicable.

0.0 Quantity more than zero but less than 0.05

${ }^{1}$ The models are proportional reductions of a specified percent for age-specific death rates in four age-group categories: all ages, ages under 25 years, ages 25 to 64 years, and ages 65 years and older. Complete elimination (100 percent reduction) is assumed for the younger age groups.

${ }^{2} \triangle$ is the difference from observed (in years): Model estimate - Observed years.

${ }^{3}$ Percent $\triangle$ is the percent difference from observed: $\triangle /$ Observed years.

${ }^{4} \mathrm{LE}$ is expected years of life.

${ }^{5}$ Observed values are from 1995

changes are more disparate, 6.4 and 3.7 years, respectively. The explanation for this finding is that, as part of the health expectancy calculation, each year of life is multiplied by the percent of the population free of activity limitation (i.e., each year of life is discounted by the percent of the population living in unhealthy states) (see the appendix). Therefore, a decrease in mortality results in an increase in total years for life expectancy, but only an increase in the healthy portion of those years for health expectancy. For example, if reducing mortality results in an increase of 10 years of life, $\mathrm{x}$ of those years may be unhealthy and 10 - $\mathrm{x}$ healthy. Consequently, the effect of reducing mortality will be greater on life expectancy, which is calculated using total years, rather than on years spent free of activity limitation. The latter is calculated using only healthy years.

\section{Impact of Changing Size of Reduction}

As the reduction of death rates gets greater (e.g., from a 5-percent to a 50-percent decrease), the increases in life and limitation-free expectancy become proportionally larger. Consider decreases in death rates for adults ages 25-64 years in table 3 . As the age-specific mortality is reduced by 5, 50, and 100 percent, the life expectancy increases $0.4,3.3$, and 6.9 percent. Expected years free of activity limitation improved by slightly smaller proportions $(0.2,2.6$, and 5.3 percent, respectively).

Years free of activity limitation as a proportion of total life expectancy (i.e., the percent of life lived free of activity limitation) decreases with larger reductions in mortality. Overall in 1995, expected years free of activity limitation as a proportion of total life expectancy was 82.1 percent (table 3). Consider mortality reductions for all ages. With a 5-percent decline in mortality, the proportion becomes 81.8 percent; with a 25 -percent decline, it becomes 81.1 percent; and with a 50-percent decline, it becomes 80.2 percent. This decrease in the proportion of life free of activity limitation, in the face of reducing mortality, occurs because much of the gain in mortality occurs in the older 
Table 4. Number of expected years free of any activity limitation due to chronic health conditions by several models of reduced activity limitation without reduced mortality

\begin{tabular}{|c|c|c|c|c|c|}
\hline & Model $^{1}$ & Years & $\begin{array}{l}\text { Percent } \\
\text { of } \mathrm{LE}^{2}\end{array}$ & $\begin{array}{l}\text { Difference } \\
\text { from } \\
\text { observed } \\
\text { value }\end{array}$ & $\begin{array}{l}\text { Percent } \\
\text { change from } \\
\text { observed } \\
\text { value }\end{array}$ \\
\hline & & \multicolumn{4}{|c|}{ No reduction in age-specific morbidity } \\
\hline \multirow[t]{2}{*}{ Observed $^{3}$. } & $\ldots \ldots$ & 62.2 & 82.1 & . & $\ldots$ \\
\hline & & \multicolumn{4}{|c|}{5 percent reduction in age-specific morbidity } \\
\hline All ages & ․․ & 62.8 & 82.8 & 0.6 & 1.0 \\
\hline Under 25 years & 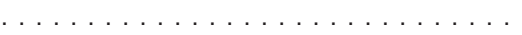 & 62.2 & 82.1 & 0.0 & 0.0 \\
\hline $25-64$ years . . & $\ldots \ldots \ldots \ldots \ldots \ldots \ldots \ldots$ & 62.5 & 82.4 & 0.3 & 0.5 \\
\hline \multirow[t]{2}{*}{ Over 64 years. } & $\ldots \ldots \ldots \ldots \ldots \ldots \ldots \ldots \ldots \ldots \ldots \ldots$ & 62.4 & 82.3 & 0.2 & 0.3 \\
\hline & & \multicolumn{4}{|c|}{10 percent reduction in age-specific morbidity } \\
\hline All ages $\ldots .$. & $\ldots \ldots \ldots \ldots \ldots \ldots$ & 63.5 & 83.8 & 1.3 & 2.1 \\
\hline Under 25 years & $\ldots \ldots \ldots \ldots \ldots \ldots \ldots$ & 62.3 & 82.2 & 0.1 & 0.2 \\
\hline $25-64$ years . . & $\ldots \ldots$ & 62.8 & 82.8 & 0.6 & 1.0 \\
\hline \multirow[t]{2}{*}{ Over 64 years } & $\ldots \ldots \ldots \ldots \ldots \ldots \ldots$ & 62.7 & 82.7 & 0.5 & 0.8 \\
\hline & & \multicolumn{4}{|c|}{25 percent reduction in age-specific morbidity } \\
\hline All ages & $\ldots \ldots \ldots \ldots$ & 65.6 & 86.5 & 3.4 & 5.5 \\
\hline Under 25 years & … & 62.5 & 82.5 & 0.3 & 0.5 \\
\hline $25-64$ years. & - & 63.7 & 84.0 & 1.5 & 2.4 \\
\hline \multirow[t]{2}{*}{ Over 64 years } & $\ldots \ldots \ldots \ldots \ldots \ldots \ldots \ldots \ldots \ldots \ldots \ldots$ & 63.6 & 83.9 & 1.4 & 2.3 \\
\hline & & \multicolumn{4}{|c|}{50 percent reduction in age-specific morbidity } \\
\hline All ages & $\ldots \ldots \ldots \ldots \ldots \ldots \ldots \ldots \ldots$ & 69.0 & 91.0 & 6.8 & 10.9 \\
\hline Under 25 years & $\ldots \ldots \ldots \ldots$ & 62.9 & 83.0 & 0.7 & 1.1 \\
\hline $25-64$ years . . & $\ldots \ldots \ldots \ldots \ldots \ldots \ldots$ & 65.3 & 86.1 & 3.1 & 5.0 \\
\hline \multirow[t]{2}{*}{ Over 64 years } & $\ldots \ldots \ldots \ldots \ldots \ldots \ldots$ & 65.1 & 85.9 & 2.9 & 4.2 \\
\hline & & \multicolumn{4}{|c|}{ Complete elimination of age-specific morbidity } \\
\hline All ages & ${ }_{1}$ & 75.8 & 100.0 & 13.6 & 21.9 \\
\hline Under 25 years & - & 63.7 & 84.0 & 1.5 & 2.4 \\
\hline 25-64 years . . & & 68.5 & 90.4 & 6.3 & 10.1 \\
\hline Over 64 years. & 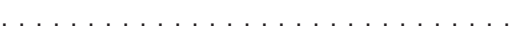 & 67.9 & 89.6 & 5.7 & 9.2 \\
\hline
\end{tabular}

Category not applicable

0.0 Quantity more than zero but less than 0.05 .

${ }^{1}$ The models are proportional reductions of a specified percent for age-specific death rates in four age-group categories: all ages, ages under 25 years, ages 25 to 64 years, and ages 65 years and older. Complete elimination (100 percent reduction) is assumed for the younger age groups.

${ }^{2}$ LE is expected life years. In 1995 the life expectancy was 75.8 years. Changing age-specific morbidity has no effect on expected life years.

${ }^{3}$ Observed values are from 1995

age groups that have greater frequency of activity limitation. The correlation between age-specific rates of reported activity limitation and mortality in 1995 was 0.95 (Spearman rank-order correlation coefficients). The years gained, therefore, are more likely to be spent in poor health than the average life year of the population. For example, with a 50 -percent decline in death rates at all ages, the expected number of life years gained is 6.4 years, but the expected number of years gained free of activity limitation is only 3.7 years. That is, only 57 percent of the years gained by reducing mortality (3.7 years/6.4 years) would be lived free of activity limitation if no change in activity limitation rates occurred. This proportion is less than the proportion for the overall population in 1995 (i.e., 82.1 percent). So the years gained are more likely to be lived in poor health compared with average life years.

\section{Mortality Reductions for Limited Age Ranges}

The effect of reducing death rates is substantially less when the reduction in mortality occurs in a limited age range. A 50-percent decrease in mortality among children and young adults (under 25 years old) increases health expectancy by only 0.5 years free of activity limitation, about one-eighth the change if death rates for all ages are affected (3.7 more years free of activity limitation). The pattern is similar for resulting changes in life expectancy. Further, when the death rates among older age groups only are reduced, the increase in either life or limitation-free expectancy is about 3 times larger than when death rates among younger ages only are affected. The greater expected years increase occurs because mortality rates are generally higher for the older ages. Consequently, the same proportional reduction in mortality among children (for example, a 50-percent reduction) is a smaller absolute decrease in mortality because the mortality rates among children are much smaller than among either of the older age groups. The calculation of expected life years is, effectively, a weighted average of the death rates (and, for health expectancy, a weighted average of mortality and 


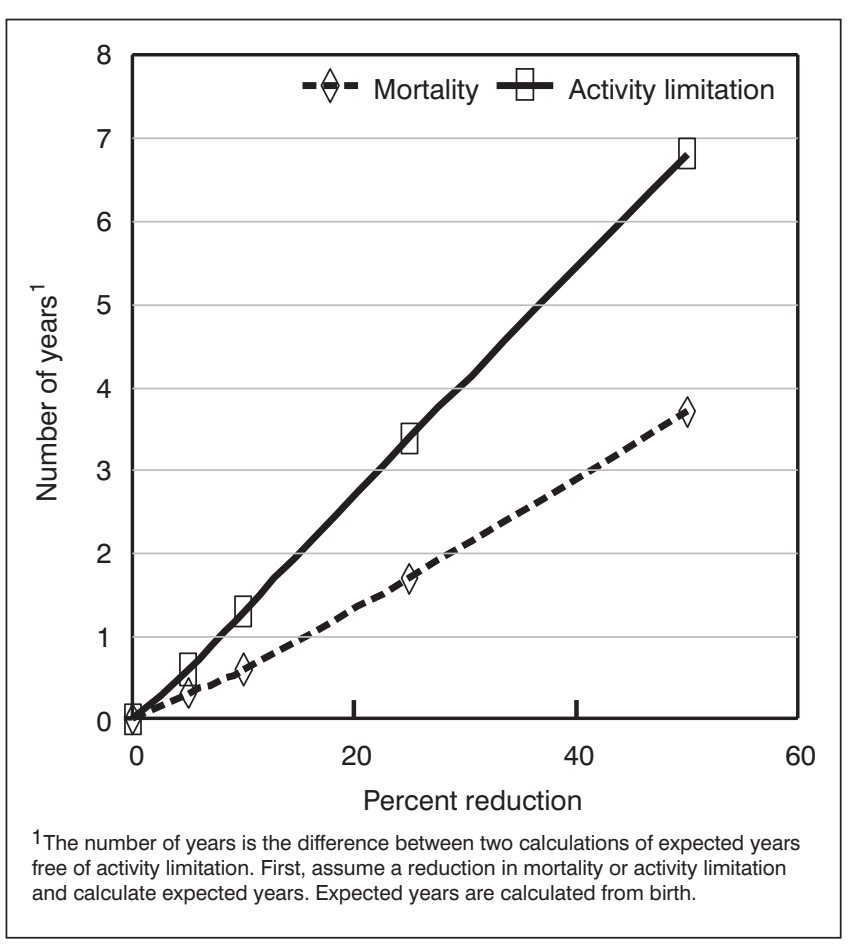

Figure 4. Change in expected years free of activity limitation by proportional reductions in either mortality or activity limitation

morbidity). Therefore, a smaller change in death rates would have a smaller change in the calculated expected years.

When reductions are limited to certain age groups, the increase in expected years free of activity limitation is greatest when the reduced death rates occur among adults aged 25-64 years although the increase in expected life years is greatest when mortality reduction occurs among the older population. In the older population, the rates of morbidity are higher than either of the two younger segments of the population. Therefore, although a reduction in death rates among the older population results in a greater number of total life years gained, those years are more likely to be spent in poor health. Therefore, the total number of quality life years gained is, in fact, less than those gained when death rate reductions occur in the 25-64 year-old population.

\section{Observed Changes Between 1985 and 1995}

The changes shown in table 3 are not strictly comparable to those in table 2. The models in table 3 assume 1995 mortality and activity limitation rates and project future changes, whereas the data in table 2 reflect past changes. However, table 3 can be used to evaluate explanations for the health expectancy changes shown in table 2 .

The decade between 1985 and 1995 had an 8-percent reduction in mortality (table 1). Assuming a comparable, modest reduction model of 10 percent for all ages, the years free of activity limitation would be expected to increase 0.6 years (table 3). This is the same as the observed increase of 0.6 years free of activity limitation between 1985 and 1995 (table 2). Therefore, the reductions in mortality alone could account for the magnitude of change in years free of activity limitation observed in this decade.

\section{Effect of Changing Morbidity}

The two principal components of health expectancy are mortality and morbidity. Models of reduction similar to the mortality models in the previous section can be applied to age-specific activity limitation rates. The sensitivity of limitation-free expectancy to reduced activity limitation is evaluated below.

Figure 3 shows the relative magnitudes of the two variables (mortality and frequency of reported activity limitation due to chronic health conditions) by age and sex. The rates of activity limitation are higher than that of mortality at all ages (rates given in table II). Even at the oldest ages, the rate of activity limitation was 3.5 times the mortality rate.

To evaluate the sensitivity of limitation-free expectancy to reduction in age-specific activity limitation, reductions of $5,10,25,50$, and 100 percent were applied to the observed 1995 frequencies of any activity limitation for four sets of age groups-all ages, less than 25 years, 25-64 years, and 65 years and older. The results of these analyses are shown in table 4.

\section{Life Expectancy Versus Health Expectancy}

For these analyses, mortality was not altered. Because life expectancy calculation depends only on mortality, under these models with change in morbidity only, life expectancy does not change from the 1995 level of 75.8 years. Changes in morbidity affect the length of life in a given quality, but not life expectancy. Consequently, expected years free of activity limitation as a proportion of expected years of life will always increase as activity limitation is reduced (i.e., expected quality years will increase but expected life years remains unchanged).

\section{Impact of Changing Reduction Size}

The effects on the number of expected years free of activity limitation when age-specific activity limitation is reduced (table 4) are similar to those noted for decreases in mortality (table 3). Larger reductions in activity limitation result in larger increases in limitation-free expectancy. As was the case when mortality was reduced, the relative impact on limitation-free expectancy is roughly proportional to the percent decrease for activity limitation. For example, when all ages are affected, a 5-percent decrease yields a change in limitation-free expectancy ( 0.6 years, table 4$)$ that is one-tenth the change produced by a 50 -percent decrease (6.8 years free of activity limitation).

However, when compared to declines in mortality, the impact of reducing age-specific activity limitation on limitation-free expectancy as a percent of life expectancy is different. In 1995, 82.1 percent of the expected life years were lived free of activity limitation. When activity limitation is reduced by 5 percent for all ages, the proportion 
becomes 82.8 percent; when it is reduced by 50 percent, the proportion is 91.0 percent; and complete elimination of activity limitation yields a health expectancy equal to life expectancy of 100 percent. Consequently, the maximum increase in expected years free of activity limitation based on 1995 data, assuming no change in mortality, is 22 percent, or 14 years. In summary, as expected, when activity limitation is reduced, the proportion of life lived free of activity limitation improves, whereas, when mortality is reduced, the proportion of life lived free of activity limitation decreases.

The magnitude of the changes in limitation-free expectancy for similar models using age-specific activity limitation are greater than changes effected using mortality. For example, a 50-percent decline in mortality at all ages produces an increase in expected years free of activity limitation of 3.7 years (table 3), but a 50-percent reduction in activity limitation produces an increase of 6.8 years (table 4 ). The impact on the expectancy is greater when activity limitation is altered because the magnitude of the rates of activity limitation is much higher than mortality at all ages.

\section{Morbidity Reduction for Limited Age Ranges}

Reducing activity limitation among the younger, middle, and older age groups of the population will result in changes in limitation-free expectancy similar to the changes resulting from reductions in mortality in these same age groups. That is, reducing activity limitation among children and young adults results in smaller changes in years free of activity limitation than either of the older age groups because the percent of the younger population with activity limitation is smaller than in older age groups. However, improvements in health expectancy are greatest when activity limitation is reduced among adults 25-64 years of age, compared with younger and older populations. Older populations have larger age-specific activity limitation rates so a proportional reduction would produce a larger change in age-specific activity limitation. However, the older age group is a smaller subgroup of the population. Thus the net effect on change in overall expected years free of activity limitation is smaller. The impact on years free of activity limitation is, therefore, a function of both the magnitude of the reduction and the proportion of the total population who benefit from the reduced activity limitation.

\section{Observed Changes Between 1985 and 1995}

The frequency of any activity limitation actually increased between 1985 and 1995 (5.3 percent, table 1). Expected years free of activity limitation, nevertheless, did increase (0.6 year, table 2) due to an 8-percent decline in mortality. If, instead of an increase, activity limitation had either not changed or had been reduced by a comparable 5 percent at all ages, larger increases in expected years free of activity limitation could have been achieved.

\section{Combined Changes in Mortality and Morbidity}

Figure 4 displays some of the findings reported above, that is, the gain in years free of activity limitation as a function of either reductions for all ages in mortality (table 3 ) or activity limitation (table 4). However, changes in mortality or morbidity rarely occur separately. Indeed, the Spearman rank-order correlation of age-specific rates of mortality and activity limitation for the 5-year age groups is almost 1.0 for 1995 (see above). Therefore, a change in one component is often associated with a change in the other. The joint impact of declines in both mortality and activity limitation are presented in table 5. As expected, the effect on life expectancy of reducing mortality only is the same as the effect of reducing both mortality and activity limitation (i.e., morbidity does not have an additional effect on life expectancy). However, reducing activity limitation in conjunction with a reduction in mortality has an additive effect on the years free of activity limitation. The consequences of combined reductions more than double the changes resulting from reductions in mortality only because the consequences of separately reducing activity limitation has greater impact than changing mortality. On the other hand, if activity limitation is actually increased when mortality is reduced, the expected years free of activity limitation can actually decrease. Again, the impacts are additive.

As noted, the effects of changes in mortality and morbidity on health expectancy are effectively additive, although the probabilities of surviving and probabilities of remaining healthy are sequentially multiplied in the life table procedures (see appendix). However, because the mortality rates are small for most age groups, these combined effects are essentially additive. That is:

$$
\left(1-\mu_{x}\right)\left(1-m_{x}\right)=1-\mu_{x}-m_{x}+\mu_{x} m_{x} \approx 1-\mu_{x}-m_{x},
$$

where $\mu_{x}$ is the mortality at age $x$ and $m_{x}$ is the morbidity of the same age group.

\section{Discussion}

Major components of summary measures of population health - the age-specific mortality and morbidity rates - are considered in this report. The relative impact of changing any component depends on the average age-specific rate, the distribution of rates, and the proportion of the population that is affected. In general, changing higher age-specific rates (e.g., morbidity as compared with mortality) or changing age-specific rates at older ages (which generally have higher age-specific rates) will have greater impact on the summary measure. Larger changes in any component will result in larger changes in the summary measure. In summary, the larger the proportion of the total population whose lives are improved, the larger the impact. These conclusions are independent of the hypothesized model.

As noted by Crimmins et al. (10) for the elderly population, declining mortality increases life expectancy and 
Table 5. Life expectancy and number of expected years free of any activity limitation due to chronic health conditions by several models of reduced mortality and activity limitation

\begin{tabular}{|c|c|c|c|c|c|c|c|}
\hline \multirow[b]{2}{*}{ Mortality } & \multirow{2}{*}{$\begin{array}{c}\text { Activity } \\
\text { limitation }\end{array}$} & \multicolumn{3}{|c|}{$\begin{array}{c}\text { Expected } \\
\text { years of life }\end{array}$} & \multicolumn{3}{|c|}{$\begin{array}{l}\text { Expected years free of } \\
\text { activity limitation }\end{array}$} \\
\hline & & Years & $\triangle^{1}$ & Percent $\triangle^{2}$ & Years & $\triangle^{1}$ & Percent $\triangle^{2}$ \\
\hline$\ldots \ldots \ldots \ldots$ & Observed $^{3}$ & 75.8 & $\ldots$ & $\ldots$ & 62.2 & $\ldots$ & $\ldots$ \\
\hline \multirow[t]{5}{*}{$5 \%$ reduction } & $10 \%$ reduction & 76.4 & 0.6 & 0.8 & 63.9 & 1.7 & 2.7 \\
\hline & $5 \%$ reduction & 76.4 & 0.6 & 0.8 & 63.2 & 1.0 & 1.6 \\
\hline & Observed $^{3}$ & 76.4 & 0.6 & 0.8 & 62.5 & 0.3 & 0.5 \\
\hline & $5 \%$ increase & 76.4 & 0.6 & 0.8 & 61.8 & -0.4 & -0.6 \\
\hline & $10 \%$ increase & 76.4 & 0.6 & 0.8 & 61.1 & -1.1 & -1.8 \\
\hline \multirow[t]{5}{*}{$10 \%$ reduction $\ldots}$. & $10 \%$ reduction & 77.0 & 1.2 & 1.6 & 64.3 & 2.1 & 3.4 \\
\hline & $5 \%$ reduction & 77.0 & 1.2 & 1.6 & 63.5 & 1.3 & 2.1 \\
\hline & Observed $^{3}$ & 77.0 & 1.2 & 1.6 & 62.8 & 0.6 & 1.0 \\
\hline & $5 \%$ increase & 77.0 & 1.2 & 1.6 & 62.1 & -0.1 & -0.2 \\
\hline & $10 \%$ increase & 77.0 & 1.2 & 1.6 & 61.4 & -0.8 & -1.3 \\
\hline
\end{tabular}

Category not applicable.

${ }^{1} \triangle$ = difference (in years): Model estimate - Observed years.

${ }^{2}$ Percent $\triangle=$ percent difference between observed value and model estimates: $\triangle /$ Observed years.

${ }^{3}$ Observed values are from 1995.

health expectancy. However, healthy life, as a proportion of total life, is decreased when mortality declines. This occurs when there is no associated reduction in morbidity. The data presented here for the decade 1985 to 1995 portray a situation in which a decrease in mortality ( 8 percent) is associated with an increase in activity limitation due to chronic health conditions ( 5 percent). This situation is consistent with the observation that reductions in mortality are sometimes characterized by the survival of people in poor health who formerly would have died (13). Reducing morbidity, on the other hand, increases both the number of healthy years and the proportion of life that is healthy because reducing morbidity in isolation of any changes in mortality does not have any impact on life expectancy. These conclusions were true regardless of the age groups affected by the reductions in either mortality or morbidity.

In this report, a number of models assuming simple proportional reductions for specified age groups were evaluated. Based on these evaluations, the improvements that can be achieved in limitation-free years are potentially much greater when activity limitation is reduced, as contrasted with mortality, because the morbidity rates are much higher than mortality rates at all ages.

The results of the models presented here can be used to estimate the size of the reduction needed to increase years free of activity limitation. For example, consider an increase of 1 additional year free of activity limitation. To achieve such a gain, either a 12-percent reduction in mortality at all ages (figure 3), a 7-percent reduction in morbidity (figure 3), or a 5-percent reduction in both mortality and morbidity (table 5) would be needed. Similar analyses could be conducted using other measures of morbidity. For example, self-assessed health status is often used to evaluate morbidity because this measure is a global evaluation of health status. Self-assessed health status can be used to calculate the expected years of good or better health. Because the age-specific rates for fair or poor health (i.e., not "good or better") are generally less than for activity limitation, larger reductions (15 percent, data not shown) are needed to result in a 1-year gain in expected years of good or better health.

The greatest increase in health expectancy can be derived by reducing morbidity and mortality concurrently. In reality, public health and medical programs to improve one aspect of health often yield some reductions in both mortality and morbidity. Consequently, the impacts on health expectancy estimated by reducing mortality alone probably underestimate the impact on health expectancy.

Current and recent past statistics are a guide to the amount of change that might be reasonably expected for years of healthy life. Although the magnitude of limitation-free expectancy statistics for the total population has not changed substantially in the past decade (table 2), the potential to alter the years free of activity limitation is large (tables 3 and 4). Between 1985 and 1995, life expectancy increased 1.1 years. The improvement noted for expected years free of activity limitation, however, only increased 0.6 years during this same time period. This indicates that this gain in life expectancy was not associated with a similar gain in years of quality health. In fact, the proportion of life lived free of activity limitation only decreased by 0.4 percent, from 82.5 percent in 1985 (61.6/74.7 years) to 82.1 percent in 1995 (62.2/75.8 years). Even without a future change in mortality, there remains an almost 14-year difference between total expected life years and expected years free of activity limitation that could be impacted with morbidity reduction.

The improvement in health at one age might be correlated with improvements at later ages. This report did not evaluate subsequent changes in either mortality or morbidity resulting from hypothesized changes to specific age groups. One disadvantage with the life table method, as it is used here and in most situations, is that the age-specific rates are all evaluated at one time period. To evaluate the potential impact of a public health policy, one would want to 
consider subsequent changes to age-specific rates of mortality or morbidity.

There are many considerations and social values that are important in the decision on how to allocate resources for public health programs. The sensitivity analyses do not address most of the considerations in that decision. The analyses presented here address the question of how reductions in mortality or morbidity produce the outcome of lengthened healthy life. The magnitude of the changes depend, however, on the measure of morbidity chosen. The higher the frequency of the morbid condition in the population, the greater the impact on healthy life expectancy of a proportional reduction in morbidity.

\section{Appendix}

\section{Calculating Expectancy Statistics}

The health expectancy statistics are calculated using the life table technique as proposed by Sullivan (8). The life table is a statistical technique used by actuaries, demographers, public health workers, and others to describe the mortality experience of a population (14). In this technique, the expectation of life $\left(e_{x}\right)$ at any given age $x$ is defined as:

$$
e_{x}=\frac{1}{1_{x}} \sum_{i=x}^{w} L_{i} \quad i=x, x+1, \ldots, w
$$

where $1_{x}$ is the number of persons alive at exact age $x, w$ is the maximum age, and $L_{i}$ represents the total number of personyears lived by a cohort in the age interval $(i, i+1)(15)$.

Expected years of healthy and unhealthy life from age $x$ are derived by partitioning the estimated life expectancy at that age, based on the morbidity experience of the population $(16,17)$. The average expected years of healthy life$\left(H E_{x}\right)$ and unhealthy life $\left(U E_{x}\right)$ at age $x$ are defined as follows:

$$
H E_{x}=\frac{1}{1_{x}} \sum_{i=x}^{w}\left(1-p_{i}\right) L_{i} \quad i=x, x+1, \ldots, w
$$

and

$$
U E_{x}=\frac{1}{1_{x}} \sum_{i=x}^{w} p_{i} L_{i} \quad i=x, x+1, \ldots, \mathrm{w}
$$

where $p_{i}$ is the prevalence rate at age $i$ of being in an unhealthy state of health.

\section{Estimating Morbidity}

The 1985 and 1995 activity limitation estimates were calculated by combining data from the National Health Interview Survey (for the prevalence of any activity limitation in the noninstitutionalized population) and National Nursing Home Survey (for the nursing home population size). For this analysis, all the nursing home residents in 1985 and 1995 are assumed to be limited in activities. Therefore, for each age group, the percent of the total population with activity limitation is estimated as:

$$
\left(f \cdot N_{N I}+N_{N H}\right) /\left(N_{N I}+N_{N H}\right)
$$

where $f$ is the age-specific prevalence of any activity limitation in the noninstitutionalized population, $N_{N I}$ is the agespecific size of the noninstitutionalized population, and $N_{N H}$ is the age-specific size of the nursing home population.

\section{Sources of Data}

\section{Population Estimates Used to Calculate Mortality}

The national population estimates used to calculate the mortality rates are derived by using the decennial census data as benchmarks and data available for interim years on births and deaths, immigrants, Armed Forces, net movement between Puerto Rico and the U.S. mainland, and Federal employees working abroad (12). These data include institutionalized and noninstitutionalized residents of the United States. The data are available from the U.S. Bureau of Census at http://www.census.gov/population/www/estimates/uspop.html.

\section{Death Statistics}

The number of deaths by age to residents of the United States are available through the National Vital Statistics System, which is maintained by the National Center for Health Statistics, Centers for Disease Control and Prevention (18). More information is available at http://www.cdc.gov/nchs.

\section{National Health Interview Survey}

The National Health Interview Survey (NHIS) was used in the estimation of morbidity in the noninstitutionalized population. NHIS, conducted by the National Center for Health Statistics, Centers for Disease Control and Prevention, is a continuing nationwide sample survey in which data are collected through personal household interviews (19). NHIS data have been collected continuously since 1957. The data in this report were collected during the surveys in 1985 and 1995. Information is obtained about the health and other characteristics of each member of the household, including data on personal, sociodemographic, and health characteristics of the family members and unrelated individuals living in these households. The sample design permits estimation of personal and health characteristics of the civilian noninstitutionalized population. More information is available at http://www.cdc.gov/nchs.

\section{National Nursing Home Survey}

The National Nursing Home Survey (NNHS) was used to estimate the size of the nursing home resident population in 1985 and 1995. For this analysis, all residents were assumed to be limited in activities. The NNHS is a periodic nationwide sample survey, conducted by the National Center for Health Statistics, Centers for Disease Control and Prevention, of nursing homes, their residents, discharges, and staff. 
The NNHS uses a two-stage probability design. The first stage selection is a probability sample of the nursing facilities, and the second stage is the selection of a sample of current residents from a list of all residents who are on the rolls of the facility as of midnight the day before the survey. Facilities included in the NNHS are nursing and related-care homes having three beds or more set up and staffed for use by residents and routinely providing nursing and personal care services. Data collected about current residents include basic demographic, living arrangement prior to admission, functional status, and other health and personal characteristics of the residents. The data on residents are collected by interviewing knowledgeable nursing home staff members. Estimates of the total resident population can be obtained by using the resident population weights (POPRES) that account for both stages of the sampling procedure. The 1985 survey had a sample size of 5,243 residents (20), and the 1995 survey had a sample size of 8,050 residents (21). More information is available at http://www.cdc.gov/nchs.

\section{Figure Data}

Tables I and II show data used in figures 1-3. Table I displays age-specific death rates for 1900 and 1995 separately by gender. Table II displays age-specific death rates and the percent of the population reporting any activity limitation due to chronic health conditions for 1995 .

\section{References}

1. National Center for Health Statistics. Health, United States, 2000, With adolescent health chartbook. Hyattsville, Maryland. 2000.

2. U.S. Department of Health and Human Services. Healthy People 2010. 2nd ed., With understanding and improving health and objectives for improving health. 2 vols. Washington: U.S. Government Printing Office. November 2000.

3. Institute of Medicine. Summarizing population health: Directions for the development and application of population metrics. Field MJ, Gold MR (eds.) Washington: National Academy Press. 1998.

4. Fryback D. Health-related quality of life for population health measures: A brief overview of the HALY family of measures. In Summarizing population health: Directions for the development and application of population metrics. Field MJ, Gold MR (eds.) Washington: National Academy Press. 1998.

5. Barendregt JJ. Degenerative disease in an aging population. Models and conjectures. Netherlands: Erasmus University. 1998.

6. Erickson P, Wilson R, Shannon I. Years of healthy life. Healthy People 2000 Statistical Notes No. 7. Hyattsville, Maryland: National Center for Health Statistics. 1995.

7. National Center for Health Statistics. Healthy People 2000 review, 1998-99. Hyattsville, Maryland: Public Health Service. 1999.

8. Sullivan DF. A single index of mortality and morbidity. HSMHA Health Reports 86 (4):347-354. 1971.
Table I. Death rates per 100,000 resident population, by age and sex: United States, 1900 and 1995

\begin{tabular}{|c|c|c|c|c|}
\hline \multirow[b]{2}{*}{ Age } & \multicolumn{2}{|c|}{ Male } & \multicolumn{2}{|c|}{ Female } \\
\hline & 1900 & 1995 & 1900 & 1995 \\
\hline All ages, crude & $1,791.1$ & 914.3 & $1,646.9$ & 846.9 \\
\hline Less than 1 year. & $17,914.4$ & 852.5 & $14,541.2$ & 695.6 \\
\hline 1-4 years. & $2,054.2$ & 44.9 & $1,912.3$ & 36.3 \\
\hline 5-14 years & 384.3 & 260.9 & 387.5 & 18.2 \\
\hline $15-24$ years & 594.0 & 139.4 & 577.6 & 47.9 \\
\hline 25-34 years & 824.3 & 206.1 & 815.2 & 77.9 \\
\hline 35-44 years & $1,067.7$ & 332.5 & 975.2 & 149.8 \\
\hline $45-54$ years & $1,569.9$ & 598.5 & $1,417.7$ & 327.5 \\
\hline 55-64 years & $2,874.1$ & $1,417.8$ & $2,576.0$ & 840.5 \\
\hline $65-74$ years & $5,929.0$ & $3,284.6$ & $5,358.3$ & $1,987.2$ \\
\hline $75-84$ years & $12,826.4$ & $7,352.7$ & $11,877.3$ & $4,870.7$ \\
\hline 85 years and over. & $26,877.2$ & $17,501.2$ & $25,517.4$ & $14,338.2$ \\
\hline
\end{tabular}

SOURCE: Centers for Disease Control and Prevention, National Center for Health Statistics. National Vital Statistics System.

Table II. Death rates and any activity limitation due to chronic health conditions, by age: United States, 1995

\begin{tabular}{|c|c|c|}
\hline Age & $\begin{array}{c}\text { Total } \\
\text { mortality }\end{array}$ & $\begin{array}{l}\text { Any activity } \\
\text { limitation }^{1}\end{array}$ \\
\hline Less than 1 year . . . . . . . . . . . & 8 & 13 \\
\hline $1-4$ years $\ldots \ldots \ldots \ldots \ldots$ & 0 & 30 \\
\hline $5-9$ years $\ldots \ldots \ldots \ldots \ldots$ & 0 & 64 \\
\hline 10-14years . . . . . . . . . & 0 & 79 \\
\hline $15-19$ years $\ldots \ldots \ldots \ldots \ldots$ & 1 & 79 \\
\hline 20-24 years $\ldots \ldots \ldots \ldots \ldots$ & 1 & 69 \\
\hline 25-29 years $\ldots \ldots \ldots \ldots \ldots$ & 1 & 81 \\
\hline 30-34 years $\ldots \ldots \ldots \ldots$ & 2 & 97 \\
\hline 35-39 years $\ldots \ldots \ldots \ldots \ldots$ & 2 & 118 \\
\hline 40-44 years $\ldots \ldots \ldots \ldots \ldots$ & 3 & 140 \\
\hline $45-49$ years $\ldots \ldots \ldots \ldots$ & 4 & 169 \\
\hline$\ldots \ldots \ldots$ & 6 & 217 \\
\hline$\ldots \ldots \ldots$ & 9 & 262 \\
\hline$\ldots \ldots \ldots \ldots$ & 4 & 311 \\
\hline$\ldots \ldots \ldots \ldots$ & 1 & 366 \\
\hline$\ldots \ldots \ldots \ldots$ & 31 & 308 \\
\hline$\ldots \ldots \ldots \ldots$ & 47 & 381 \\
\hline 80-84 years $\ldots \ldots \ldots \ldots \ldots$ & 75 & 480 \\
\hline 85 years and over . . . . . . . . . & 152 & 657 \\
\hline
\end{tabular}

${ }^{1}$ Activity limitation includes both the frequency of activity limitation reported by the noninstitutionalized population and the proportion of the population in nursing homes, who are all assumed to have activity limitation.

NOTE: Rates are shown as number per 1,000 population.

SOURCES: Centers for Disease Control and Prevention, National Center for Health Statistics. National Vital Statistics System (mortality); National Health Interview Survey (noninstitutionalized population); National Nursing Home Survey (nursing home population).

9. Molla M, Wagener DK, Madans JH. Summary measures of population health: Methods for calculating health expectancy. Healthy People Statistical Notes No. 21. Hyattsville, Maryland: National Center for Health Statistics. 2001.

10. Crimmins EM, Hayward MD, Saito Y. Changing mortality and morbidity rates and the health status and life expectancy of the older population. Demography 31(1):159-175. 1994.

11. Crimmins E, Hayward M, Saito T. Differentials in active life expectancy in the older population of the United States. J Gerontology: Social Sciences 51B(3):S111-S120. 1996.

12. U.S. Bureau of the Census. U.S. population estimated by age, sex, race, and Hispanic origin: 1990-96. Release PPL-57. March 1997. 
13. Gordis L. Epidemiology. 2nd ed. Philadelphia, Pennsylvania: WB Saunders. 2000.

14. Namboodiri K, Suchindran CM. Life table techniques and their applications. Orlando, Florida: Academic Press. 1987.

15. Jagger C. Health expectancy calculation by the Sullivan method: A practical guide. NUPRI Research Paper Series No. 68. Tokyo, Japan. 1999.

16. Keyfitz N. Applied mathematical demography. 2nd. ed. New York, NY: Springer-Verlag. 1985.

17. Mathers CD. Health expectancy in Australia 1981 and 1988. Technical Report. Australian Institute of Health: AGPS, Canberra. 1991.

18. National Center for Health Statistics. Technical appendix, Vital statistics of the United States, 1992. Vol II. Mortality. DHHS
Pub. No. (PHS) 96-1101. Washington: U.S. Government Printing Office. 1996.

19. Bensen V, Marano MA. Current estimates from the National Health Interview Survey, 1995. National Center for Health Statistics. Vital Health Stat 10(199). 1998.

20. Hing E. Nursing home utilization by current residents: United States, 1985. National Center for Health Statistics. Vital Health Stat 13(102). 1989.

21. Gabrel C, Jones A. The National Nursing Home Survey:1995 Summary. National Center for Health Statistics. Vital Health Stat 13(146). 2000.

Selected published issues of Healthy People Statistical Notes

\begin{tabular}{lll}
\hline \multicolumn{1}{c}{ Number } & \multicolumn{1}{c}{ Title } & Date of Issue \\
\hline Healthy People 2000 & & Winter 1991 \\
2 & Infant Mortality & March 1995 \\
6 & Direct Standardization (Age-Adjusted Death Rates) & April 1995 \\
7 & Years of Healthy Life & November 2000 \\
19 & Healthy People 2000: An Assessment Based on the Health Status & Indicators for the United States and Each State \\
& & January 2001 \\
Healthy People 2010 & Age Adjustment Using the 2000 Projected U.S. Population & August 2001 \\
20 & Summary Measures of Population Health: Methods for & \\
\hline
\end{tabular}

NOTE: These issues of Healthy People Statistical Notes deal with statistical issues affecting the tracking of Healthy People 2010. 
DEPARTMENT OF

HEALTH \& HUMAN SERVICES

FIRST CLASS MAIL

Centers for Disease Control and Prevention POSTAGE \& FEES PAID $\mathrm{CDC} / \mathrm{NCHS}$

National Center for Health Statistics

PERMIT NO. G-284

6525 Belcrest Road

Hyattsville, Maryland 20782-2003

\section{OFFICIAL BUSINESS}

PENALTY FOR PRIVATE USE, $\$ 300$

To receive this publication regularly, contact the National Center for Health Statistics by calling 301-458-4636

E-mail: nchsquery@cdc.gov

Internet: www.cdc.gov/nchs/

\section{Suggested citation}

Wagener DK, Molla MT, Crimmins EM, Pamuk E, Madans JH. Summary measures of population health: Addressing the first goal of healthy people 2010, improving health expectancy. Statistical Notes, no. 22. Hyattsville, Maryland: National Center for Health Statistics. September 2001. 